\title{
Experimental investigations of stringer on chassis frame in TATA 2516 TC Truck
}

\author{
B. Stalin ${ }^{1 *}$, M. Ravichandran ${ }^{2}$, K. Sathiya Moorthi ${ }^{3}$ and C. Ramesh Kannan ${ }^{4}$ \\ Assistant Professor, Department of Mechanical Engineering, Anna University, Regional Campus Madurai, \\ Keelakuilkudi, Tamilnadu, India ${ }^{1}$ \\ Professor, Department of Mechanical Engineering, Chennai Institute of Technology, Kundrathur, Tamilnadu, India ${ }^{2}$ \\ PG Scholar, Department of Mechanical Engineering, Anna University, Regional Campus Madurai, Keelakuilkudi, \\ Tamilnadu, India ${ }^{3}$ \\ Associate Professor, Department of Mechanical Engineering, Karpagam Academy of Higher Education, Tamilnadu, \\ India $^{4}$
}

\section{(C)2018 ACCENTS}

\begin{abstract}
Automotive chassis is very important part of carrying the entire load of all essential components like engine, propeller shaft, differential, gear box, braking system, suspension, etc. Moreover chassis should be high stiffness and high strong enough to withstand high amounts of twisting and bending loads which are subjected on it. In this paper, stringer component is fabricated and tested experimentally in the universal testing machine (UTM) testing machine. Stringer component should resist the maximum load and it must exhibit high strength and high stiffness. The method followed to achieve the high strength stringer is an experimental failure analysis of the structure while the structure is subjected to 3point bending in a universal testing machine. The two different stringer structures are selected for experimental failure analysis under 3- point bending action and the component is taken from the Tata 2516 TC truck chassis. The stringer component is taken in two forms. They are C-stringer, and Hat stringer. The testing is carried out in bending by applying the load on centre to the stringer. The breaking loads, the deformation of the stringer at breaking load, ultimate stress are calculated on the UTM testing machine. After that, the graph between stress-strain, stress-deformation, and loaddeformation is obtained from testing. From the results, the strength of the hat stringer is more than the strength of the $C$ stringer.
\end{abstract}

\section{Keywords}

C-stringer, Hat stringer, UTM testing machine.

\section{Introduction}

The stringer is a component of chassis frame which is used to resist the entire truck load on bending. The stringers used on the chassis are C-stringer, hat stringer, I-stringer, T-stringer, L-stringer and so on. The chassis and the stringer should be manufactured with maximum strength and maximum stiffness on bending.

Patel and Chitransh [1] have done the analysis on existing heavy vehicle chassis of TATA 2518 TC for different material properties. The model of the chassis is pictured by using Catia V5 software and analysed by using Ansys 14.0. After analysis, the results are correlated between the existing structures in steel chassis.

\footnotetext{
*Author for correspondence
}

The stress analysis is done on the Pro-Mechanica software and the max stress generated on the chassis is found out. The displacement analysis is also calculated which deformation value is in safe condition. The maximum strain value is also determined in the analysis. Finally, the shear stress reacted on the TC 2516 chassis is also gathered from the analysis [2]. Patel et al. [3] has described the optimization of weight on the chassis of truck 2516TC by changing the sections taken on the frame of the chassis. The sections taken on the chassis are $\mathrm{C}$-stringer, I-stringer, rectangular stringer, and modified C-stringer. Bertolini et al. [4] has analysed the omega stringer in experimentally and numerically by using 3 point bending machine and a numerical study was taken and deals the influence of a refined mesh made into account resin fillets. Vescovini et al. [5] has done the post buckling response failure analysis of the multi composite stringer on the panels 
using numerical models. Finally, a global/local damage analysis method is taken in which a detailed local model is used to verify the global model and find the locations that are the most dangerous for damage tolerance. Azzi et al. [6] has found out the properties of the SS 304 material which is treated by duplex material by using Plasma nitradizing which is used to configure this work on SS 304 Material.

Petersen and Hühne [7] has performed the work that holds a methodology to execute a feasible design for stiffened shells. Parametric studies, including criteria like stability, strength and damage tolerance, are done. Additionally, a static compression experiment is performed. Christian Mittelstedt has done a closedform analysis method of the local postbuckling behaviour of aircraft panels that are braced by hatstringers.

In the present work, the main objective to improve the load withstanding capacity of the stringer which is fitted to the chassis. So that improves the strength of the stringer, the number of stringers which are placed on the frame will be reduced in this investigation. The existing framework contains $7 \mathrm{C}$ stringers, hence we are analysed to reduce that count of C-stringers used in existing frame instead of new hat stringer. We are tested, the both stringers against 3 point bending action.

\section{Methodology}

First of all, the structure of the component selection is the major criteria for attaining the maximum strength and maximum stiffness. The already shown stringer on the chassis is $\mathrm{C}$-stringer, and now, we are going to prove that stringer is higher in strength while compared to the $\mathrm{C}$-stringer. The structure of the $\mathrm{C}$ stringer is pictured as per the dimension and the testing model is also fabricated in the ratio of 5:1 which is represented in Figure 1.
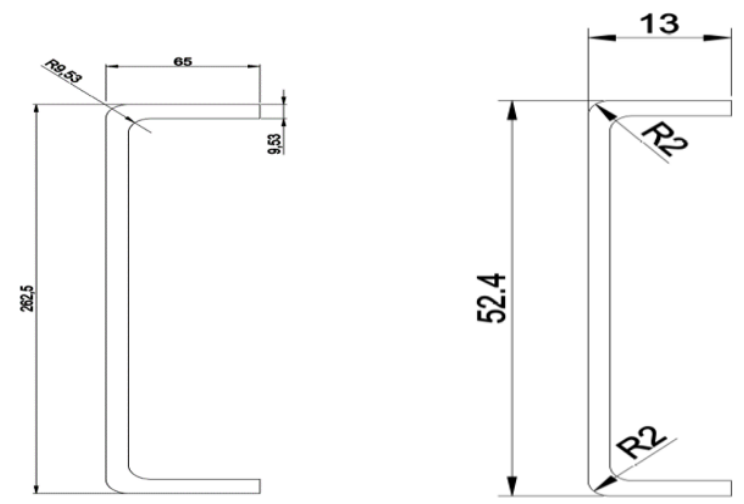

Figure $1 \mathrm{C}$-stringer and C-stringer model
After the C-stringer, the hat stringer dimensions are predicted and the fabricated model dimension is also taken with a scaling ratio of $5: 1$ which is represented in Figure 2. The hat stringer is reordered on the top fillet up to $40 \mathrm{~mm}$ because it will reduce the stress distribution on the structure.

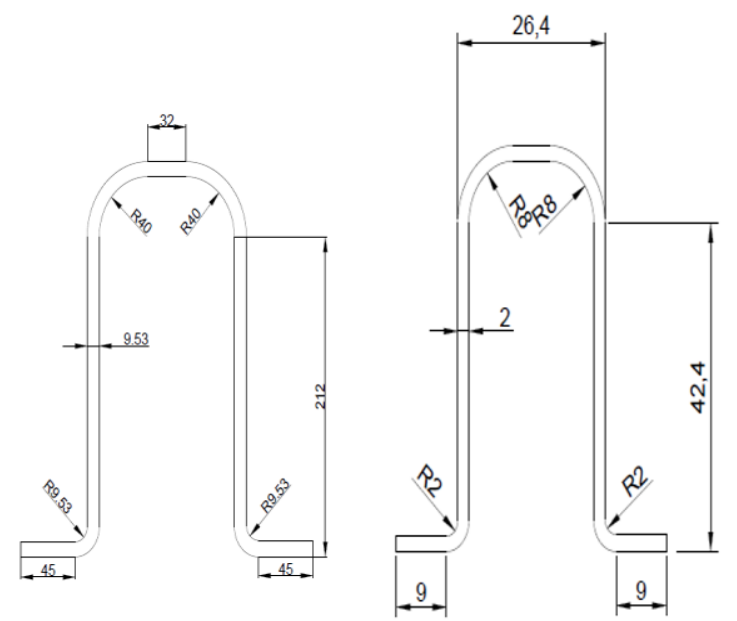

Figure 2 Hat stringer and hat stringer model

\section{Experimental analysis}

The experimental setup is prepared to test the model C-stringer and the model hat stringer in the UTM testing Machine. The component is fixed at both ends and the load is applied on the middle of the structure. The fabricated component is done from the plate formation of the original formation by bending action on the plates. The plate dimensions for $\mathrm{C}$-stringer and hat stringer are $50 \mathrm{~mm}$ length, $90 \mathrm{~mm}$ width, $2 \mathrm{~mm}$ thickness for C-stringer, and 500mm length, $160 \mathrm{~mm}$ width, $2 \mathrm{~mm}$ thickness for hat stringer respectively. The plate is bent to the required shape by using the Hydraulic press. The original component of $\mathrm{C}$ stringer and hat stringer is shown in Figure 3 and Figure 4. The material selected for the component fabrication is stainless steel 304.

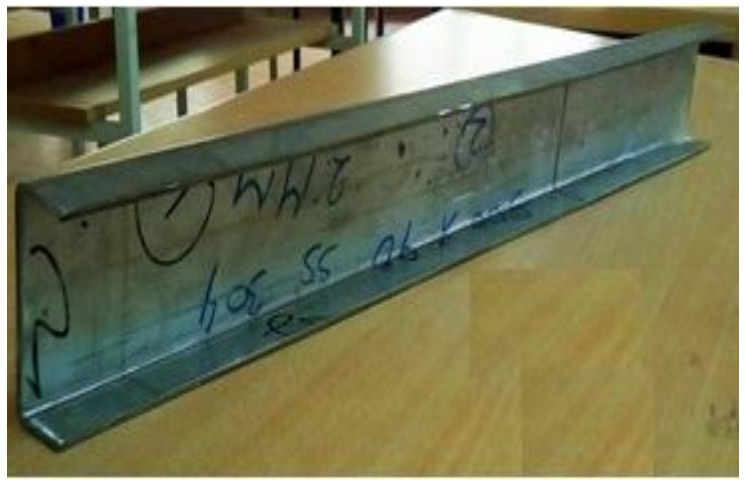

Figure 3 Fabricated C-stringer 


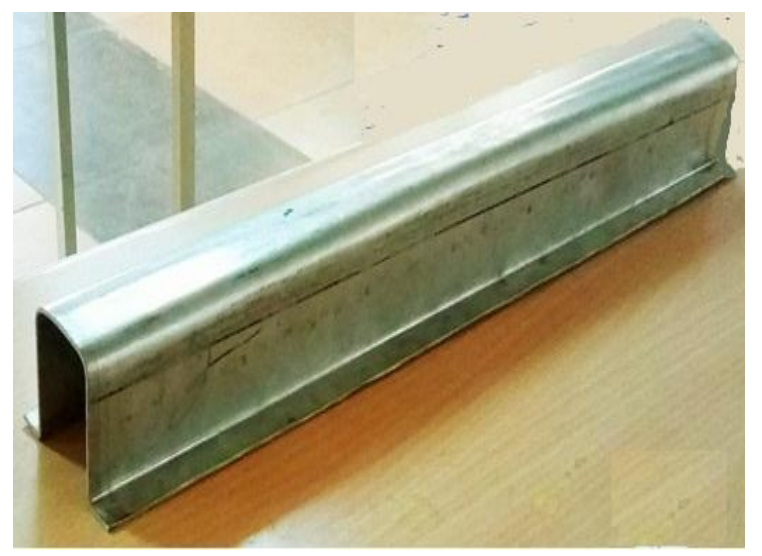

Figure 4 Fabricated hat stringer

\section{Results and discussion}

The testing of the component in the UTM machine is on the basis of 3 point bending load. From that, the breaking load, deformation, ultimate stress is calculated. The experimental setup is shown in Figure 5 and Figure 6.

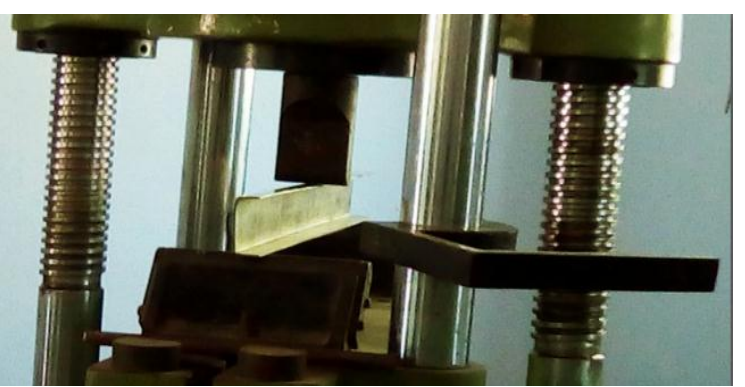

Figure 5 Experimental setup for C-stringer

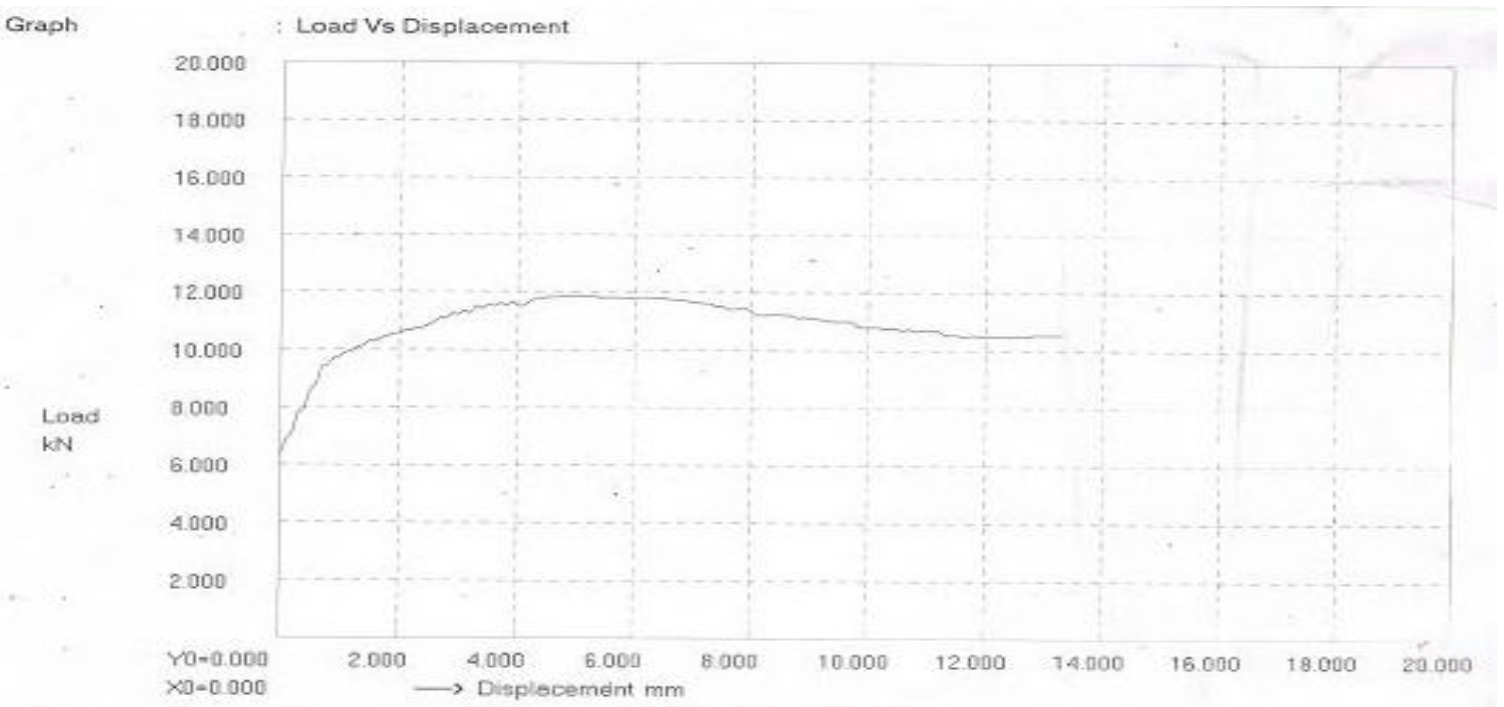

Figure 7 Load-displacement curve for C-stringer 
International Journal of Advanced Technology and Engineering Exploration, Vol 5(43)
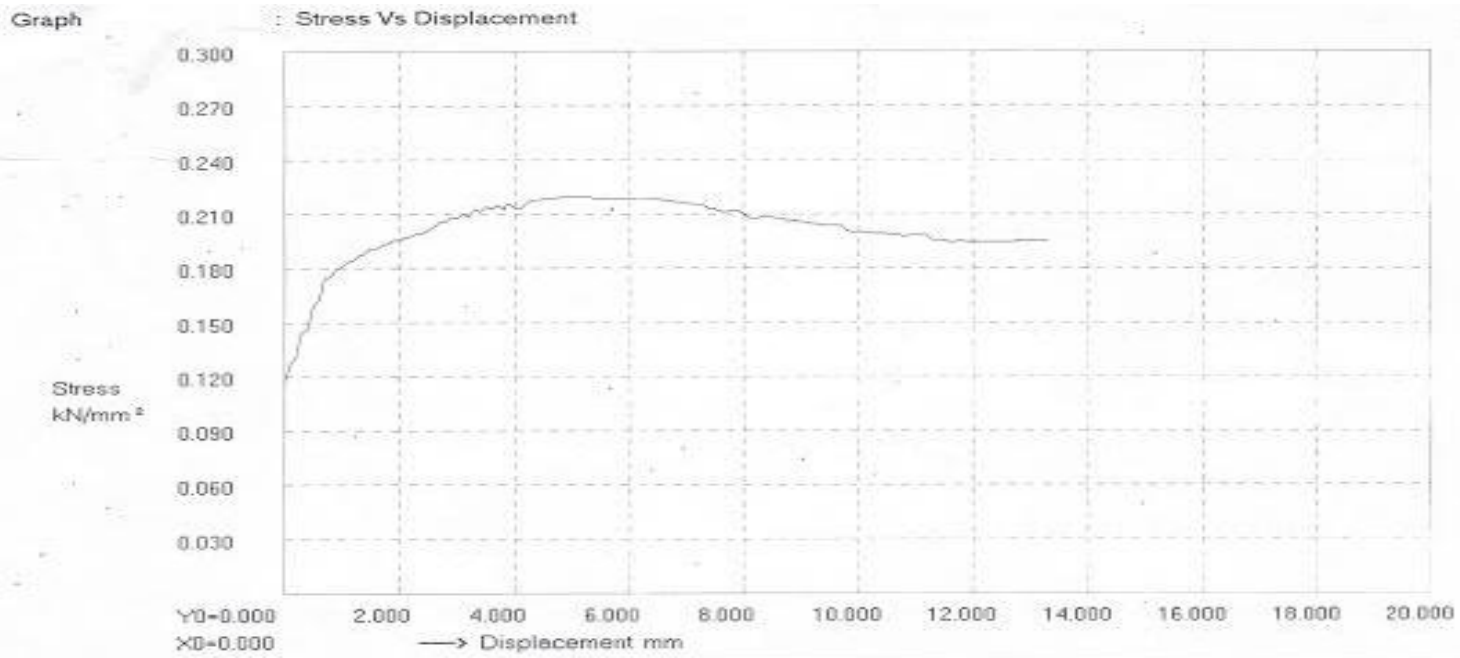

Figure 8 Stress-displacement curve for C- stringer

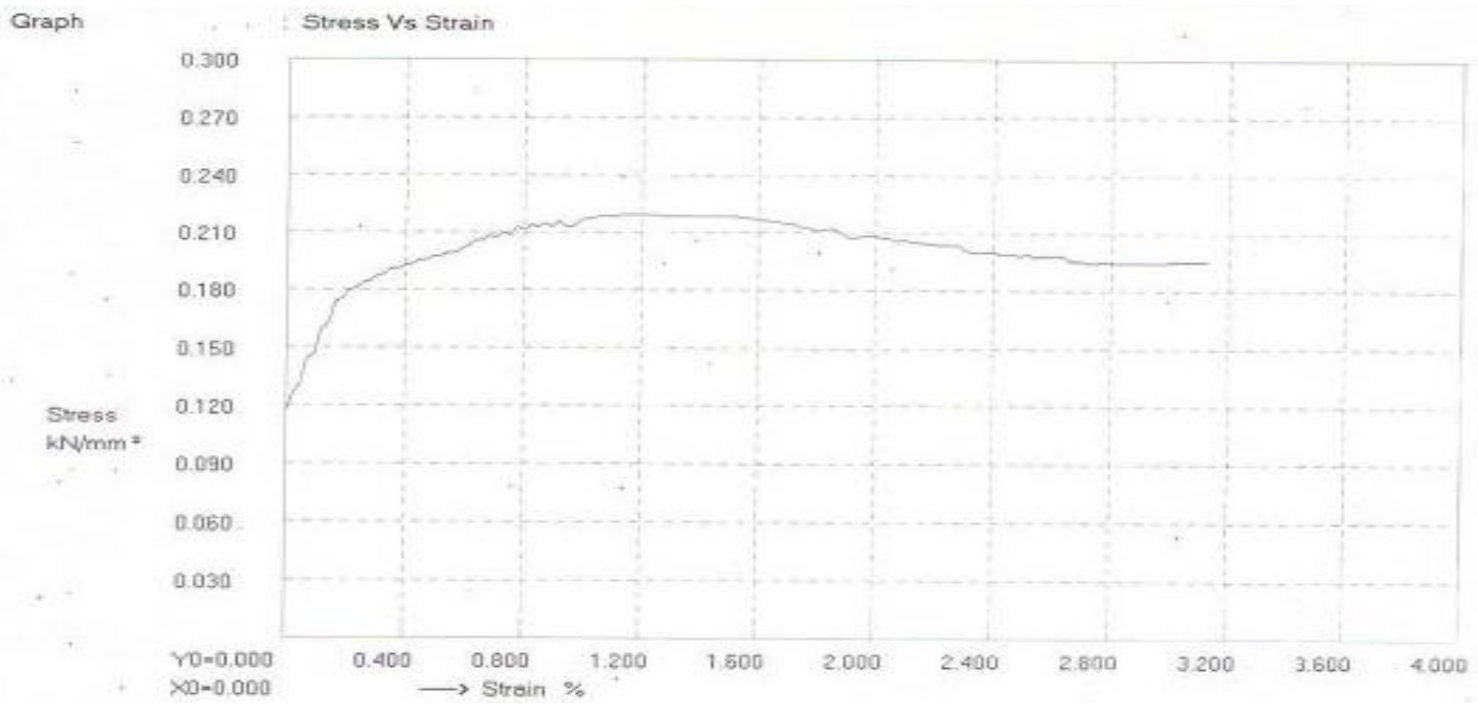

Figure 9 stress-strain curve for C-stringer

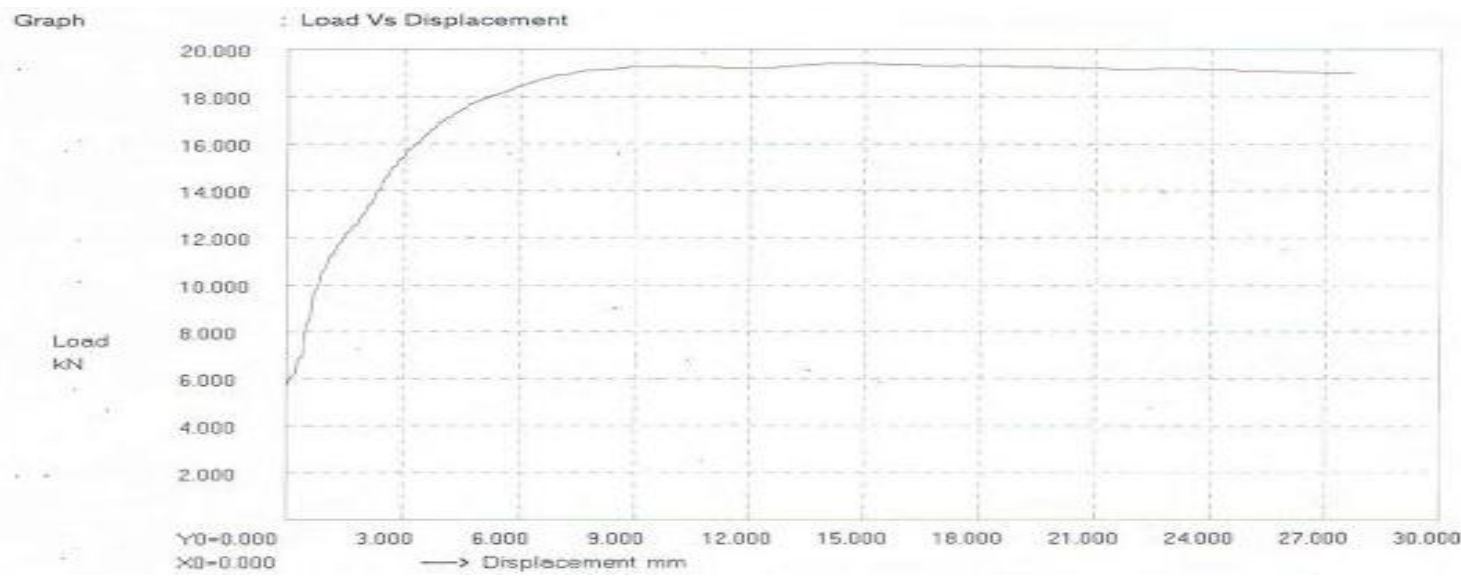

Figure 10 Load-displacement curve for hat stringer

121 
Stalin et al.

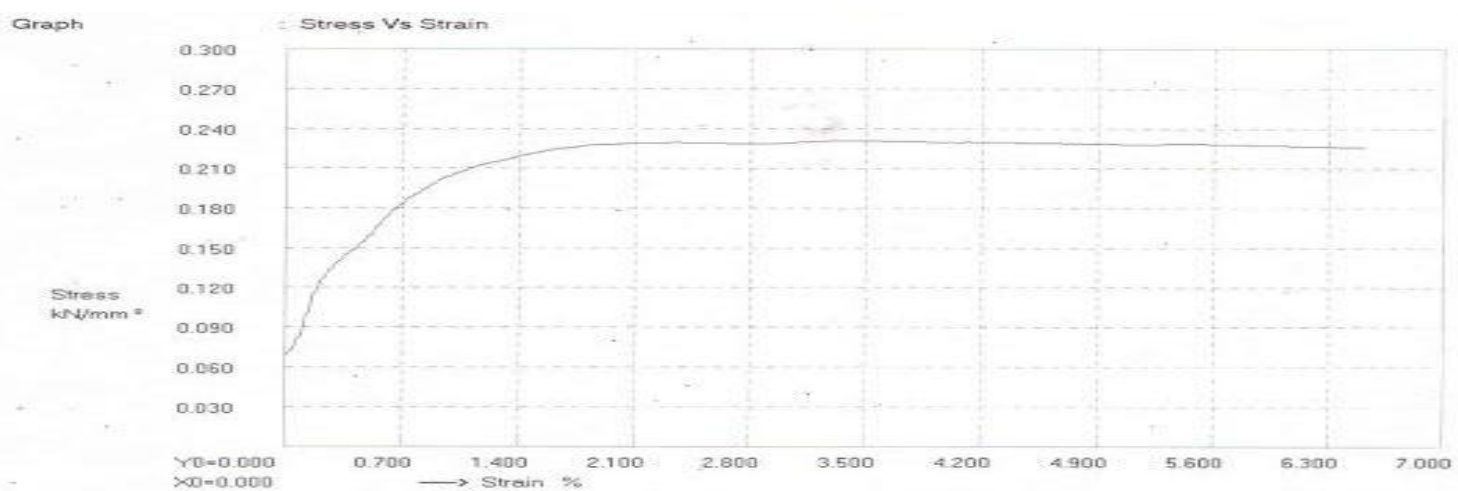

Figure 11 Stress-displacement curve for hat stringer

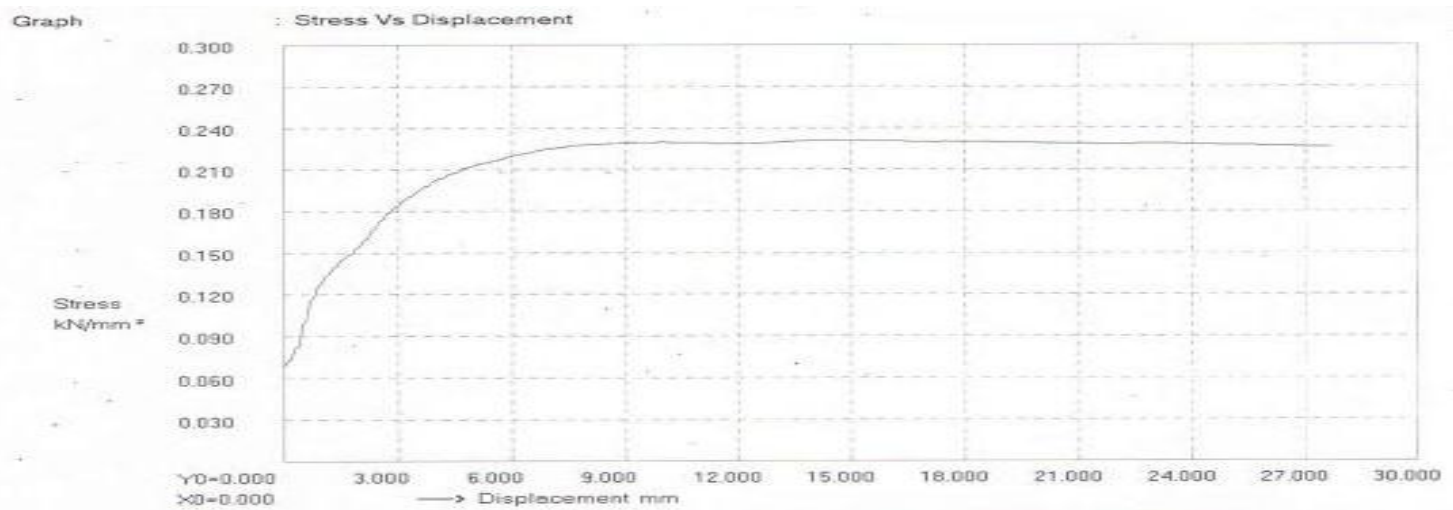

Figure 12 Stress-strain curve for hat stringer

\section{Conclusion}

From the experimental result, the hat stringer results are better than the $\mathrm{C}$-stringer results. The breaking load of the hat stringer is $19.05 \mathrm{KN}$ which is greater than the $\mathrm{C}$-stringer breaking load of $11.85 \mathrm{KN}$.

The ultimate stress distribution of hat stringer is greater than the C-stringer ultimate stress distribution. The deformation occurred in the maximum loading condition of hat stringer is greater than the $\mathrm{C}$-stringer deformation at maximum loading condition. In the future, we will find a number of hat stringer required in between the framework to withstand the entire load of the truck. It can be attained by finite element analysis of the entire chassis with the $\mathrm{C}$-stringer and hat stringer.

\section{Acknowledgment}

The authors thank the Department of Mechanical Engineering, Anna University, Regional Campus Madurai for providing partial support for carrying out this research work.

\section{Conflicts of interest}

The authors have no conflicts of interest to declare.

\section{References}

[1] Patel AS, Chitransh J. Modeling, analysis \& optimization of TATA 2518 TC truck chassis frame using CAE tools. International Journal of Engineering Research \& Technology. 2016; 5(10):70-80.

[2] Patel RL, Gawande KR, Morabiya DB. Design and analysis of chassis frame of TATA 2516TC. International Journal for Research in Applied Science and Engineering Technology. 2014. 2(3): 115-9.

[3] Patel MR, Morabiya MD, Rathour MA. Weight optimization of chassis frame using Pro-Mechanica. SSRG International Journal of Mechanical Engineering. 2014; 1(8):4-8.

[4] Bertolini J, Castanié B, Barrau JJ, Navarro JP. An experimental and numerical study on omega stringer debonding. Composite Structures. 2008; 86(1-3):23342.

[5] Vescovini R, Davila CG, Bisagni C. Failure analysis of composite multi-stringer panels using simplified models. Composites Part B: Engineering. 2013; 45(1):939-51.

[6] Azzi M, Benkahoul M, Klemberg-Sapieha JE, Martinu L. Corrosion and mechanical properties of duplextreated 301 stainless steel. Surface and Coatings Technology. 2010; 205(5):1557-63.

[7] Petersen E, Hühne C. Potential of cross section varying $\Omega$ stringer made of carbon fibre reinforced plastics. Thin-Walled Structures. 2016; 103:253-62. 
Stalin. B was born in Rajapalayam, Virudhunagar district, Tamilnadu, India, in 1981. He received B.E. Degree in Mechanical Engineering from the University of Madras, Tamilnadu, India, in 2002, and M.E. Degree in Manufacturing Engineering from the Anna University, Tamilnadu, India, in 2008. He obtained his Ph.D in Mechanical Engineering discipline, in 2015 at Anna University, Chennai, Tamilnadu, India. He has been currently working as an Assistant Professor in the Department of Mechanical Engineering, Anna University, Regional Campus Madurai, Tamilnadu, India since 2010. He is a Life Member of the Indian Society for Technical Education (ISTE) and The Institution of Engineers (India). His current research interests include Optimization Technology, Manufacturing Engineering, Composite Materials, Material Characterization, Mechanical Properties.

Email: stalin1312@gmail.com 